\title{
Malignant Peripheral Nerve Sheath Tumor
}

National Cancer Institute

\section{Source}

National Cancer Institute. Malignant Peripheral Nerve Sheath Tumor. NCI Thesaurus.

Code C3798.

An uncommon, highly aggressive malignant tumor, arising from the peripheral nerves and affecting mostly adults in their third to sixth decades of life. It usually occurs in medium-sized and large nerves of the buttock, thigh, upper arm, or the paraspinal region. It may be associated with neurofibromatosis 1 (NF1). 